\title{
SARS CoV-2: Recomendaciones de limpieza y desinfección en entornos comunitarios
}

\author{
Dr. Eduardo López Mora \\ Dr. Rodrigo Cruz Choappa
}

Centro de Diagnóstico e Investigación de Enfermedades Infecciosas (CDIEI)

Universidad de Valparaíso

Autor para correspondencia: rodrigo.cruz@uv.cl

\section{Contexto del problema}

Al inicio de la pandemia hubo datos publicados que lograron demostrar la persistencia de SARS -CoV-2 en ciertas superficies y materiales, generando seria preocupación acerca del rol de transmisión a través del contacto con superficies contaminadas, lo cual llevo al desarrollo de políticas de limpieza y desinfección en espacios públicos, que implican un alto costo y potenciales riesgo para la salud ante un uso inadecuado de estos productos. Estos datos iniciales de persistencia en materiales, en entornos controlados de laboratorio actualmente parecen no ser extrapolables a la vida real ${ }^{1}$.

Dado el conocimiento actualizado, el mecanismo principal por el cual las personas se contagian con SARS-CoV-2 es a través de la exposición a gotitas respiratorias y aerosoles en espacios cerrados. El riesgo de transmisión a través del contacto con superficies u objetos contaminados se considera muy bajo ${ }^{1}$.

En abril de 2021 los Centros para el Control y Prevención de Enfermedades (CDC) de EE. UU. publicó actualizaciones sobre recomendaciones de limpieza y desinfección en entornos extrahospitalarios basadas en la evidencia científica actualizada ${ }^{1}$. Este documento busca enfatizar ciertas estrategias de control en espacios públicos y el hogar, difundiendo así un uso racional de productos de limpieza y desinfección.

\section{Características del Virus SARS CoV-2 y riesgo de persistencia en el ambiente}

El SARS-CoV-2 es un virus envuelto, por lo que cuenta con una bicapa lipídica que lo protege del medio ambiente. Esta envoltura es lábil y puede degradarse rápidamente al entrar en contacto con agentes de limpieza y en condiciones ambientales habituales no controladas ${ }^{2}$.

\section{Persistencia en superficies}

En entornos de laboratorio, con control de factores ambientales, se reportó que, en superficies porosas se dejaba de detectar virus viables en minutos u horas, en cambio en superficies no porosas, se reportó virus viable durante días. $\mathrm{La}$ aparente inactivación relativamente más rápida de $\mathrm{SARS}-\mathrm{CoV}-2$ en superficies porosas podría atribuirse a la acción capilar dentro de los poros y la evaporación más rápida de las gotitas ${ }^{3,4}$.

Los datos de los estudios de viabilidad viral en superficies indican que se puede esperar una reducción del $99 \%$ en condiciones ambientales interiores dentro de 72 horas en superficies comunes no porosas como acero inoxidable, plástico y vidrio, destacando que estos datos no 
SARS CoV-2: Recomendaciones de limpieza y desinfección en entornos comunitarios - López E.

consideran factores relevantes como la cantidad de virus (inoculo), factores ambientales que pueden inactivar al virus $\mathrm{u}$ otras como la ventilación del lugar, la ineficiencia en la transferencia del virus entre superficies a las manos y de estas a la boca, la nariz u ojos ${ }^{5}$.

\section{Riesgo de transmisión a través de mecanismos de contacto con superficies contaminadas}

Se han realizado estudios de evaluación cuantitativa de riesgo microbiológico (ECRM) para estimar el riesgo relativo de transmisión. Los hallazgos de estos estudios sugieren que a través de contacto con superficies contaminadas el riesgo es muy bajo, menor de 1 en $10.000^{6}$.

Existen escasos reportes de casos de COVID-19 potencialmente atribuidos a la transmisión por contacto con superficies. Siendo el escenario teórico aquel que se transmite entre personas al tocar superficies sobre las que una persona enferma ha tosido o estornudado recientemente, siendo además necesario el contacto directo de las manos con la boca, la nariz o las conjuntivas.

En ambientes externos se puede esperar que las concentraciones de SARS-CoV-2 sean más bajas que en las superficies interiores debido a la dilución y el movimiento del aire, así como a las condiciones ambientales adversas.

Otro estudio de ECRM evaluó la efectividad de las medidas de prevención que reducen el riesgo de transmisión por fómites, siendo la higiene de las manos clave en reducir sustancialmente el riesgo de transmisión del SARS-CoV-2 de superficies contaminadas, mientras que la desinfección de superficies una o dos veces al día no tuvo un impacto significativo ${ }^{7}$.

Se ha demostrado que la desinfección de superficies es eficaz para prevenir la transmisión secundaria del SARS-CoV-2 entre una persona infectada y otro miembro familiar dentro del hogar, sin embargo, no hay evidencia que apoye que el uso rutinario de desinfectantes en entornos comunitarios, ya sea en interiores o exteriores, sea útil para prevenir la transmisión del SARS-CoV-2 a través de fómites.

La limpieza de rutina realizada con jabón o detergente, al menos una vez al día, puede reducir sustancialmente los niveles de virus en las superficies, solo en situaciones en las que ha habido un caso sospechoso o confirmado de COVID-19 dentro de las últimas 24 horas, la presencia de virus en las superficies es más probable y, por lo tanto, las superficies de alto contacto deben además desinfectarse con alcohol al $70 \%$, cloro $\mathrm{u}$ otro producto desinfectante.

\section{CONCLUSIONES}

Las personas pueden infectarse con SARS-CoV2 a través del contacto con superficies, sin embargo, según los datos disponibles la transmisión a través de contacto con superficies o materiales contaminados no es la ruta principal por la que se propaga el SARS-CoV-2 y se considera que el riesgo es bajo.

En la mayoría de las situaciones, limpiar las superficies con jabón o detergente, y no desinfectar, es suficiente para reducir el riesgo. Se recomienda la desinfección en entornos comunitarios cerrados donde se ha sospechado o confirmado un caso de COVID-19 en las últimas 24 horas. El riesgo de transmisión por fómites se puede reducir con el uso consistente de mascarilla, higiene de manos, distanciamiento social y una limpieza adecuada de superficies.

\section{REFERENCIAS}

1. Science Brief: SARS-CoV-2 and Surface (Fomite) Transmission for Indoor Community Environments. CDC. Update. 2021. https://www.cdc.gov/coronavirus/2019- 
SARS CoV-2: Recomendaciones de limpieza y desinfección en entornos comunitarios - López E.

ncov/more/science-and-research/surface-

transmission.html.

2. Chin A, Chu J, Perera M, Hui K, Yen HL,

Chan M, et al. Stability of SARS-CoV-2 in different environmental conditions. Lancet Microbe. 2020. doi.org/10.1016/ S26665247(20)30003-3.

3. Chatterjee S, Murallidharan JS, Agrawal A, Bhardwaj R. Why coronavirus survives longer on impermeable than porous surfaces. Physics of Fluids. 2021. doi: 10.1063 / 5.0037924 .

4. Xie C, Zhao H, Li K, Zhang Z, Lu X, Peng $\mathbf{H}$, et al. The evidence of indirect transmission of SARS-CoV-2 reported in Guangzhou, China, BMC Public Health. 2020. https://doi.org/10.1186/s12889-02009296-y.

5. Mondelli M, Colaneri M, Seminari E, Baldanti F, Bruno R. Low risk of SARS$\mathrm{CoV}-2$ transmission by fomites in real-life conditions. The Lancet. 2021. doi: 10.1016 / S1473-3099 (20) 30678-2.

6. Harvey AP, Fuhrmeister ER, Cantrell ME, Pitol AK, Powers JE, Nadimpalli ML, et al. Longitudinal monitoring of SARS-CoV-2 RNA on high-touch surfaces in a community setting, Environmental Science \& Technology Letters. 2020. doi: 10.1101/ 2020.10.27.20220905.

7. Pitol AK, Julian TR. Community transmission of SARS-CoV-2 by fomites: Risks and risk reduction strategies. Environmental Science and Technology Letters. 2020. https://doi.org/10.1021/acs.estlett.0c00966. 